\title{
Alelopatia de Joanesia princeps Vell. e Casearia sylvestris Sw. sobre espécies cultivadas
}

\author{
Rafael Aguiar Capobiango, Silvane Vestena, Alexandre Horácio Couto Bittencourt*
}

\author{
Curso de Farmácia, Faculdade de Minas, Avenida Cristiano Ferreira Varella 655, Bairro Universitário, \\ 36800-000 Muriaé-MG, Brasil
}

\begin{abstract}
RESUMO: Metabólitos secundários produzidos em algumas plantas podem provocar alterações no desenvolvimento de outras plantas ou até mesmo de outros organismos. O objetivo do trabalho foi avaliar o efeito alelopático de extratos aquosos de folhas de Joanesia princeps e Casearia sylvestris na germinação e no desenvolvimento inicial de plântulas de Brassica oleracea cv. capitata, Lactuca sativa cv. grand rapids e Lycopersicum esculentum. Foram testadas seis concentrações de cada extrato $(10,30,50,70,90$ e 100\%) além do controle água destilada. Os extratos aquosos de $J$. princeps e $C$. sylvestris reduziram e, ou inibiram significativamente o percentual de geminação das sementes, o crescimento inicial da parte aérea e do sistema radicular de todas as espécies cultivadas e causaram severas anormalidades nas plântulas. Os resultados indicam a existência de potencial alelopático de $J$. princeps e C. sylvestris.
\end{abstract}

Unitermos: Joanesia princeps, Euphorbiaceae, Casearia sylvestris, Salicaceae, alelopatia, germinação, crescimento.

\begin{abstract}
Allelopathy of Joanesia princeps Vell. and Casearia sylvestris Sw. on the cultivated species". Secondary metabolites produced in some plant species can provoke development changes in other plants or even in other organisms. The objective of this work was to identify the possible allelopathic effects of the aqueous extracts of Joanesia princeps and Casearia sylvestris leaves in the germination and initial growth of Brassica oleracea cv. capitata, Lactuca sativa cv. grand rapids and Lycopersicum esculentum seedlings. Six concentrations of each extract $(10,30,50,70,90$ and 100\%) were tested besides distilled water control. The aqueous extracts of $J$. princeps and C. sylvestris significantly reduced the seed germination percentage, initial growth of the aerial section and root system of all cultivated species in which they caused severe seedlings damage. The results indicate existence of allelopathic potential in J. princeps and C. sylvestris.
\end{abstract}

Keywords: Joanesia princeps, Euphorbiaceae, Casearia sylvestris, Salicaceae, allelopathy, germination, growth.

\section{INTRODUÇÃO}

Algumas plantas produzem compostos do metabolismo secundário que atuam inibindo ou favorecendo o processo germinativo bem como o processo de divisão celular. Estes compostos são conhecidos como alelopáticos. O termo alelopatia refere-se à capacidade que as plantas têm de interferir no desenvolvimento de outras plantas, por meio de substâncias que liberam na atmosfera ou, quase sempre, no solo (Medeiros, 1990; Ferreira \& Borghetti, 2004). A ação alelopática se dá através do efeito destas substâncias aliado às condições ambientais. A alelopatia pode ser um fator determinante do sucesso ou insucesso no cultivo de plantas (Ferreira \& Borghetti, 2004).

A ação visível dos aleloquímicos sobre as plantas é somente uma sinalização secundária de mudanças anteriores. Assim, os estudos referentes ao efeito de aleloquímicos sobre a germinação e, ou desenvolvimento da planta são manifestações secundárias de processos ocorridos a nível molecular e celular inicialmente (Ferreira \& Áquila, 2000; Ferreira \& Borghetti, 2004). A maioria dos estudos em alelopatia refere-se apenas ao efeito do aleloquímico sobre a germinação e o crescimento da plantateste, sem considerar os eventos celulares relacionados às mudanças fisiológicas e genéticas (Pires et al., 2001; Iganci et al., 2006).

Dentre as espécies com possível potencial alelopático destacam-se a cutia (Joannesia princeps Vell.). Joanesiaprinceps (Euphorbiaceae)éumaárvore encontrada nas regiões norte, nordeste e sudeste, principalmente em floresta pluvial de mata atlântica (Azevedo \& Silva, 2006; Lopes et al., 2002). Os frutos contêm, geralmente, duas amêndoas que possuem $37 \%$ de óleo, sendo útil para fins medicinais e industriais (Chaves \& Davide, 1996). Adicionalmente, Waibel et al. (2003) relatam a presença de 
taninos, saponinas e glicosídeos cianogênicas na semente de cutia e, sendo esta, utilizada na medicina popular como purgativo, para perturbações menstruais, febre perniciosa, antimicrobiano, sífilis, escrofulose e inchaço.

Casearia sylvestris Sw. (Salicaceae), possui propriedades medicinais, como ações hemostática, anestesiante e cicatrizante de lesões na pele e mucosa (Scavone et al., 1979), ações diurética e diaforética e boa atividade contra peçonhas de animais (Rizzini et al., 1988). Basile et al. (1990), demonstraram a ação preventiva desta planta contra úlcera gástrica, herpes, sífilis e depurativo do sangue. A espécie tem se caracterizado pela ocorrência de substâncias de interesse como: cumarinas, flavonóides, lignanas e diversos diterpenos (Lorenzi \& Matos, 2002). Estudos mostraram que um de seus compostos secundários mais importantes, a casearina, tem atividade antitumoral e citotóxica (Ruggiero et al., 2002).

Considerando a importância que representam como espécies para recomposição, preservação e fornecimento de matéria-prima à indústria farmacêutica, aliados a carência de informações quanto ao processo de alelopatia, realizou-se este trabalho com o objetivo de verificar o potencial alelopático de folhas secas de guaçatonga e sementes de cutia sobre a germinação de sementes e o desenvolvimento de plântulas de repolho (Brassica oleracea L. cv. capitata), alface (Lactuca sativa L. cv. grand rapids) e tomate (Lycopersicum esculentum Miller).

\section{MATERIAL E MÉTODOS}

As folhas de guaçatonga e as sementes de cutia foram coletadas no Parque Municipal Monteiro Lobato, Muriaé-MG, e no município de Guiricema-MG, respectivamente. $\mathrm{O}$ material botânico foi identificado por especialistas da Universidade Federal de Viçosa e, posteriormente, incorporado na coleção didática de Plantas Medicinais da Faminas, com os números Joanesia princeps, 201, Casearia sylvestris, 215 e confirmado a identificação junto à coleção do Herbário VIC. O material foi seco em estufa de circulação forçada de ar a $40{ }^{\circ} \mathrm{C}$ até obtenção de massa seca estável. Os experimentos foram conduzidos no Laboratório de Bioquímica da Faculdade de Minas, Muriaé-MG.

Para a realização dos bioensaios de germinação foram utilizados sementes de repolho, alface e tomate. Foram efetuados testes preliminares em laboratório para verificação da viabilidade e do vigor da germinação das sementes. Para a obtenção do extrato aquoso de Casearia sylvestris e Joanesia princeps foram utilizadas folhas e sementes, respectivamente, previamente secas na concentração de $1 \mathrm{~g} 10 \mathrm{~mL}^{-1}$ (peso/volume) e trituradas em um liquidificador. A mistura foi deixada em repouso por 48 h a $5 \pm 1{ }^{\circ} \mathrm{C}$, sendo, após, filtrada em funil de Büchner, por duas vezes, usando-se papel filtro qualitativo. $\mathrm{O}$ extrato foi diluído em seis concentrações diferentes $(10,30,50$,
$70,90,100 \%$ ) e utilizado água destilada como tratamento controle, sendo que para a concentração de $100 \%$ foi utilizado o "extrato puro".

Para os bioensaios de germinação foram utilizadas placa-de-petri esterilizadas de $9 \mathrm{~cm}$ de diâmetro, forradas com dois discos de papel-filtro, sendo umedecidas com 7 $\mathrm{mL}$ de água destilada (tratamento controle) ou do extrato aquoso. Dez sementes das espécies cultivadas por placade-petri com cinco repetições constituíram a unidade amostral. Foram consideradas germinadas as sementes que apresentaram $2 \mathrm{~mm}$ de protusão radicular (Brasil, 1992). O experimento foi mantido por um período de dez dias, sendo que diariamente foi verificado o número de sementes germinadas. Para os dados do crescimento das plântulas foi coletado, no final dos dez dias de experimento, o comprimento em centímetros da raiz e da parte aérea com auxílio de um paquímetro.

A determinação do índice de velocidade de germinação (IVG) das sementes foi realizada conforme Maguire (1962), por meio de contagens diárias do número de sementes germinadas.

$\mathrm{O}$ experimento foi montado em um delineamento inteiramente casualizado. Os resultados obtidos foram submetidos à análise de variância (ANOVA) e as médias, analisadas pelo teste Tukey a $5 \%$ de probabilidade (Beiguelman, 2002).

\section{RESULTADOS E DISCUSSÃO}

Os extratos aquosos de sementes de cutia reduziram e, ou inibiram a germinação de repolho, alface e tomate, sendo que a redução aumentou com o aumento das concentrações utilizadas (Tabelas 1, 2 e 3).

Para o repolho a germinação das sementes foi reduzida a partir da concentração de $30 \%$, quando comparado ao tratamento controle. Já para o alface ocorreu inibição na germinação a partir da concentração de $70 \%$. As sementes mais tolerantes aos extratos aquosos de cutia foram a de tomate, sendo observada apenas redução no percentual de germinação na concentração mais elevada, quando comparado ao tratamento controle (Tabelas 1, 2 e 3), redução esta de $45,8 \%$.

Ao contrário do ocorrido com a germinação das sementes, o crescimento inicial das plântulas de repolho sofreu forte influência dos extratos aquosos de cutia, sendo que a partir da concentração de $70 \%$, foi observado inibição no crescimento. No sistema radicular e na parte aérea de alface também foi observado inibição do crescimento a partir da concentração de 50\% (Tabelas 1 e 2).

Como observado para o percentual de germinação de tomate, o crescimento inicial não sofreu inibição em presença dos extratos aquosos de cutia e, sim apenas redução, sendo esta aumentada com o aumento das concentrações utilizadas. A redução foi observada a partir da concentração de $30 \%$, quando comparado ao tratamento controle (Tabela 3 ). 
As folhas de guaçatonga, também apresentou efeito alelopático sobre as espécies testadas, sendo que para todos os parâmetros analisados ocorreu diminuição com o aumento das concentrações utilizadas (Tabelas 4, 5 e 6).

Para as sementes de repolho e de alface a germinação foi reduzida nas mais altas concentrações (90 e 100\%), quando comparado ao tratamento controle. Estas reduções foram de 29,1 e $46,1 \%$, respectivamente para repolho e 55,1 e 79,6\%, respectivamente para alface (Tabelas 4 e 5). Já para o tomate, o percentual de germinação foi reduzido a partir da concentração de $50 \%$, quando comparado ao tratamento controle (Tabela 6). Independente da espécie testada, o percentual de germinação diminuiu com o aumento das concentrações utilizadas.

Como observado para o percentual de geminação, o crescimento inicial das plântulas sofreu redução em presença dos extratos aquosos de guaçatonga, exceto para alface onde apenas na concentração mais elevada foi observada inibição no crescimento tanto para o sistema radicular como para a parte aérea (Tabelas 4,5 e 6 ).

Para o repolho o crescimento do sistema radicular foi reduzido a partir da concentração de $30 \%$ e da parte aérea a partir de $50 \%$, quando comparado ao tratamento controle. Já para o alface o crescimento do sistema radicular foi reduzido a partir da concentração de $30 \%$ e da parte aérea a partir da concentração de $70 \%$, quando comparado ao tratamento controle; enquanto que, o sistema radicular de tomate foi reduzido a partir da concentração de $10 \%$ e da parte aérea a partir de $50 \%$, quando comparado ao tratamento controle (Tabelas 4, 5 e 6 ).

Os resultados do presente estudo indicaram que as sementes e plântulas em desenvolvimento se mostraram mais sensíveis aos extratos aquosos de cutia quando comparado aos de guaçatonga, com inibições no percentual de germinação e no crescimento inicial das plântulas e, dentre as espécies, alface se mostrou a mais sensível.

No presente experimento, o índice de velocidade de germinação (IVG) foi afetado pelos extratos aquosos de cutia e de guaçatonga. Com os extratos de cutia, repolho e alface o índice de velocidade de germinação diminuiu a partir da concentração de $10 \%$ e para tomate foi verificado redução a partir da concentração de $30 \%$ (Tabelas 1, 2 e 3) e, com os extratos de guaçatonga, para repolho e tomate o índice de velocidade de germinação diminuiu a partir da concentração de $30 \%$ e,a partir da concentração de $50 \%$ para alface, quando comparado ao tratamento controle, sendo que esta variável diminuiu com o aumento das concentrações dos extratos utilizadas (Tabelas 4, 5 e 6).

Nos estudos alelopáticos, a germinabilidade é um índice muito usado, embora não demonstre outros aspectos do processo de germinação, como atrasos, já que envolve apenas resultados finais, ignorando períodos de germinação inativa no decorrer do bioensaio (Chiapuso et al., 1997). Muitas vezes, o que se observa são efeitos significativos de extratos sobre o tempo médio e velocidade germinação e nenhuma diferença na germinabilidade, em relação ao controle (Ferreira e Áquila, 2000), sendo que o mesmo foi verificado nos bioensaios realizados com as espécies testadas.

Os aleloquímicos podem agir de maneira diversa dependendo do ambiente e do estágio do ciclo vital em que a planta alvo se encontra, visto que ambos refletem diferentes estados fisiológicos. Além disso, os efeitos também podem ser variados quando se considera em qual órgão da planta eles estão atuando (Áquila, 2000). Resultados semelhantes foram verificados no presente trabalho onde independente das espécies testadas observou-se que a estrutura vegetal que mais sofreu o efeito dos extratos de folhas secas de guaçatonga e sementes de cutia foi o sistema radicular, pois é a parte vegetal que primeiro mantém contato com o extrato aquoso. Reduções estas que também foram intensificadas com o aumento das concentrações dos extratos utilizados.

Em muitos estudos, o que se observa é um efeito alelopático mais pronunciado sobre o desenvolvimento inicial de uma plântula alvo quando comparado à germinação, já que este último processo utiliza reservas da própria semente (Miró et al., 1998; Áquila, 2000). Entretanto, os resultados obtidos no presente estudo revelaram efeitos tanto sobre o desenvolvimento vegetativo quanto sobre a germinação. Alterações no percentual de germinação e índice de velocidade de germinação (Tabelas 1, 2, 3, 4, 5 e 6), indicam, segundo Bewley \& Black (1978) e Labouriau (1983), interferências nas reações metabólicas que culminam na germinação. Quanto ao desenvolvimento inicial, geralmente se constata uma redução no tamanho do eixo-hipocótilo-raiz da planta alvo (Áquila, 2000; Rodrigues, 2002), sendo que este mesmo efeito foi obtido nos tratamentos com extratos de folhas secas guaçatonga $\mathrm{e}$ sementes de cutia.

As substâncias alelopáticas, presentes em cutia, tais como saponinas e taninos podem apresentar mecanismos de ação indiretos e diretos. Os efeitos indiretos incluem alterações nas propriedades e status nutricional do solo, bem como nas populações e, ou atividades de microrganismos. Já os efeitos diretos, que são mais estudados, incluem alterações no metabolismo vegetal, podendo afetar as características citológicas, os fitormônios, as membranas, a germinação, a absorção mineral, a respiração, a atividade enzimática, a divisão celular, entre outros (Rice, 1984; Rizvi \& Rizvi, 1992).

Os efeitos visíveis causados por aleloquímicos são reflexos secundários de alterações que ocorrem a nível molecular (Rizvi \& Rizvi, 1992). Cruz-Ortega et al. (1998) relatam que o endurecimento e escurecimento dos ápices radiculares são evidências de alterações morfológicas e ultra-estruturais causadas por fitotoxinas. Este aspecto de escurecimento nas raízes foi observado nos tratamentos com extratos de cutia e guaçatonga e também em outros estudos de alelopatia (Pellissier, 1993; Rodrigues, 2002; 
Maraschin-Silva \& Áquila, 2006).

Segundo Soares \& Vieira (2000), o efeito tóxico causado em raízes de alface submetidas a extratos aquosos de algumas espécies da família Gleicheniaceae, visualizado pela redução de tamanho e necrose, é semelhante ao dano provocado por detergentes naturais, tais como as saponinas. Saponinas e taninos foram sugeridos como possíveis aleloquímicos encontrados em extratos aquosos de folhas de Myrciaria cuspidata Berg., de acordo com Rodrigues (2002). Considerando-se o processo de germinação em sementes de algodão, já foi sugerido que as saponinas atuam reduzindo a taxa respiratória, devido a uma menor difusão do oxigênio através do tegumento, inibindo a germinação dessa planta (Marchaim et al., 1974).

Vários estudos na literatura mostraram que extratos de plantas podem inibir a germinação de sementes não necessariamente devido aos seus constituintes químicos, mas sim em função do potencial osmótico do extrato. Em outros bioensaios realizados com extratos aquosos de folhas de guaçatonga e de sementes de cutia, os extratos foram caracterizados quanto ao $\mathrm{pH}$ e potencial osmótico (estimado pelo método de Chardakov, Salisbury e Ross), sendo que os extratos apresentaram valores de $\mathrm{pH}$ e potencial osmótico dentro do que se considera adequando para a germinação e desenvolvimento das espécies cultivadas (Chou \& Young, 1974; Elakovich, 1999; Áquila, 2000). Assim, pode-se excluir uma interferência desses fatores nos efeitos observados sobre estas espécies cultivadas.

O potencial alelopático de cutia e guaçatonga verificado no presente estudo pode ser uma estratégia para seu estabelecimento inicial, retardando o de outras plantas potencialmente competidoras, assim como apontado por Piña-Rodrigues \& Lopes (2001) para algumas pioneiras. A dominância de muitas espécies pioneiras também pode ser favorecida por outras características desse grupo ecológico, tais como produção de sementes pequenas e em grande quantidade, rápido crescimento e maturação, intolerância à sombra e plasticidade fenotípica (Válio \& Scarpa, 2001). Em suma, uma série de fatores pode contribuir para essa dominância, incluindo-se a alelopatia. Deste modo, outras abordagens experimentais devem ser realizadas para se ter uma maior compreensão dos resultados obtidos, bem como para confirmar se este potencial alelopático se expressa em condições naturais, atestando a alelopatia de cutia e de guaçatonga.

Tabela 1. Efeito alelopático de extratos aquosos de sementes de cutia (Joanesia princeps) sobre repolho (Brassica oleracea cv. capitata).

\begin{tabular}{ccccc}
\hline \multirow{2}{*}{ Concentração (\%) } & Germinação (\%) & \multicolumn{2}{c}{ Crescimento (cm) } & IVG \\
\cline { 3 - 4 } Controle & $100 \pm 0,00 \mathrm{a}$ & $3,5 \pm 0,32 \mathrm{a}$ & Sistema Radicular & $8,3 \pm 0,05 \mathrm{a}$ \\
10 & $100 \pm 0,00 \mathrm{a}$ & $2,2 \pm 0,26 \mathrm{ab}$ & $6,4 \pm 1,70 \mathrm{a}$ & $4,4 \pm 0,15 \mathrm{~b}$ \\
30 & $68 \pm 0,55 \mathrm{~b}$ & $1,4 \pm 1,57 \mathrm{~b}$ & $3,6 \pm 0,44 \mathrm{~b}$ & $1,3 \pm 0,25 \mathrm{c}$ \\
50 & $32 \pm 1,14 \mathrm{bc}$ & $0 \pm 0,00 \mathrm{c}$ & $0,5 \pm 0,19 \mathrm{c}$ & $1,0 \pm 0,04 \mathrm{c}$ \\
70 & $16 \pm 1,30 \mathrm{~cd}$ & $0 \pm 0,00 \mathrm{c}$ & $0 \pm 0,00 \mathrm{c}$ & $0,8 \pm 0,02 \mathrm{~cd}$ \\
90 & $4 \pm 0,45 \mathrm{~d}$ & $0 \pm 0,00 \mathrm{c}$ & $0 \pm 0,00 \mathrm{c}$ & $0,5 \pm 0,32 \mathrm{~d}$ \\
100 & $4 \pm 0,45 \mathrm{~d}$ & $0 \pm 0,00 \mathrm{c}$ & $0 \pm 0,00 \mathrm{c}$ & $0,2 \pm 0,05 \mathrm{~d}$ \\
\hline CV $(\%)$ & 13,45 & 9,76 & $0 \pm 0,00 \mathrm{c}$ & 19,54 \\
\hline
\end{tabular}

As médias \pm desvio padrão seguidas pelas mesmas letras nas linhas não diferem significativamente pelo teste Tukey a $5 \%$ de probabilidade.

Tabela 2. Efeito alelopático de extratos aquosos de sementes de cutia (Joanesia princeps) sobre alface (Lactuca sativa cv. grand rapids).

\begin{tabular}{|c|c|c|c|c|}
\hline \multirow{2}{*}{ Concentração (\%) } & \multirow{2}{*}{ Germinação (\%) } & \multicolumn{2}{|c|}{ Crescimento $(\mathrm{cm})$} & \multirow[b]{2}{*}{ IVG } \\
\hline & & Parte Aérea & Sistema Radicular & \\
\hline Controle & $100 \pm 0,00 \mathrm{a}$ & $6,9 \pm 0,62 \mathrm{a}$ & $7,9 \pm 0,37 \mathrm{a}$ & $6,5 \pm 0,65 \mathrm{a}$ \\
\hline 10 & $72 \pm 1,52 \mathrm{ab}$ & $3,0 \pm 0,76 \mathrm{~b}$ & $1,6 \pm 0,21 \mathrm{~b}$ & $3,8 \pm 0,47 \mathrm{~b}$ \\
\hline 30 & $52 \pm 1,67 \mathrm{~b}$ & $0,6 \pm 0,2 \mathrm{a}$ & $0,4 \pm 0,25 \mathrm{c}$ & $2,0 \pm 0,33 \mathrm{c}$ \\
\hline 50 & $12 \pm 0,55 \mathrm{c}$ & $0 \pm 0,00 \mathrm{c}$ & $0 \pm 0,00 \mathrm{c}$ & $0,5 \pm 0,09 \mathrm{~d}$ \\
\hline 70 & $0 \pm 0,00 \mathrm{c}$ & $0 \pm 0,00 \mathrm{c}$ & $0 \pm 0,00 \mathrm{c}$ & $0,0 \pm 0,00 \mathrm{~d}$ \\
\hline 90 & $0 \pm 0,00 \mathrm{c}$ & $0 \pm 0,00 \mathrm{c}$ & $0 \pm 0,00 \mathrm{c}$ & $0,0 \pm 0,00 \mathrm{~d}$ \\
\hline 100 & $0 \pm 0,00 \mathrm{c}$ & $0 \pm 0,00 \mathrm{c}$ & $0 \pm 0,00 \mathrm{c}$ & $0,0 \pm 0,00 \mathrm{~d}$ \\
\hline CV $(\%)$ & 11,73 & 12,79 & 15,61 & 10,69 \\
\hline \multicolumn{5}{|c|}{$\begin{array}{l}\text { As médias } \pm \text { desvio padrão seguidas pelas mesmas letras nas linhas não diferem significativamente pelo teste Tukey a } 5 \% \text { de } \\
\text { probabilidade. }\end{array}$} \\
\hline & & & & $\begin{array}{l}\text { Rev. Bras. Farmacogn. } \\
\text { Braz. J. Pharmacogn. } \\
\text { 19(4): Out./Dez. } 2009\end{array}$ \\
\hline
\end{tabular}


Tabela 3. Efeito alelopático de extratos aquosos de sementes de cutia (Joanesia princeps) sobre tomate (Lycopersicum esculentum).

\begin{tabular}{ccccc}
\hline \multirow{2}{*}{ Concentração (\%) } & Germinação (\%) & \multicolumn{2}{c}{ Crescimento (cm) } & IVG \\
\cline { 3 - 4 } Controle & $96 \pm 0,45 \mathrm{a}$ & $4,4 \pm 0,36 \mathrm{a}$ & Sistema Radicular & $8,2 \pm 0,57 \mathrm{a}$ \\
10 & $84 \pm 0,45 \mathrm{ab}$ & $4,4 \pm 0,39 \mathrm{a}$ & $4,2 \pm 0,60 \mathrm{a}$ & $7,5 \pm 0,54 \mathrm{a}$ \\
30 & $80 \pm 0,71 \mathrm{ab}$ & $3,1 \pm 0,39 \mathrm{~b}$ & $4,1 \pm 0,37 \mathrm{a}$ & $3,6 \pm 0,96 \mathrm{~b}$ \\
50 & $80 \pm 0,71 \mathrm{ab}$ & $2,1 \pm 0,19 \mathrm{c}$ & $1,8 \pm 0,18 \mathrm{~b}$ & $2,9 \pm 0,07 \mathrm{~b}$ \\
70 & $76 \pm 0,84 \mathrm{ab}$ & $1,7 \pm 0,25 \mathrm{c}$ & $1,2 \pm 0,23 \mathrm{bc}$ & $1,2 \pm 0,52 \mathrm{c}$ \\
90 & $68 \pm 1,52 \mathrm{ab}$ & $1,1 \pm 0,16 \mathrm{~cd}$ & $0,8 \pm 0,08 \mathrm{~cd}$ & $0,9 \pm 0,03 \mathrm{c}$ \\
100 & $52 \pm 0,55 \mathrm{~b}$ & $0,7 \pm 0,15 \mathrm{~d}$ & $0,5 \pm 0,19 \mathrm{~d}$ & $0,6 \pm 0,07 \mathrm{c}$ \\
\hline CV $(\%)$ & 8,43 & 9,54 & $0,3 \pm 0,04 \mathrm{~d}$ & 16,75 \\
\hline
\end{tabular}

As médias \pm desvio padrão seguidas pelas mesmas letras nas linhas não diferem significativamente pelo teste Tukey a $5 \%$ de probabilidade.

Tabela 4. Efeito alelopático de extratos aquosos de folhas secas de guaçatonga (Casearia sylvestris) sobre repolho (Brassica oleracea cv. capitata).

\begin{tabular}{ccccc}
\hline \multirow{2}{*}{ Concentração (\%) } & Germinação (\%) & \multicolumn{2}{c}{ Crescimento (cm) } & IVG \\
\cline { 2 - 4 } Controle & $96 \pm 0,55 \mathrm{a}$ & $4,4 \pm 0,26 \mathrm{a}$ & Sistema Radicular & $5,2 \pm 0,08 \mathrm{a}$ \\
10 & $94 \pm 0,89 \mathrm{a}$ & $4,0 \pm, 41 \mathrm{a}$ & $7,5 \pm 0,09 \mathrm{a}$ & $4,8 \pm 0,85 \mathrm{a}$ \\
30 & $90 \pm 0,71 \mathrm{a}$ & $2,8 \pm 0,47 \mathrm{ab}$ & $7,4 \pm 0,97 \mathrm{a}$ & $1,4 \pm 0,57 \mathrm{~b}$ \\
50 & $88 \pm 0,84 \mathrm{a}$ & $1,8 \pm 0,56 \mathrm{~b}$ & $2,9 \pm 0,55 \mathrm{~b}$ & $1,0 \pm 0,96 \mathrm{~b}$ \\
70 & $70 \pm 1,00 \mathrm{ab}$ & $0,3 \pm 0,13 \mathrm{c}$ & $0,6 \pm 0,32 \mathrm{c}$ & $0,9 \pm 0,12 \mathrm{~b}$ \\
90 & $68 \pm 1,30 \mathrm{~b}$ & $0,2 \pm 0,03 \mathrm{c}$ & $0,2 \pm 0,00 \mathrm{~cd}$ & $0,4 \pm 0,65 \mathrm{c}$ \\
100 & $56 \pm 0,55 \mathrm{~b}$ & $0,0 \pm 0,00 \mathrm{c}$ & $0,2 \pm 0,08 \mathrm{~d}$ & $0,3 \pm 0,14 \mathrm{c}$ \\
\hline CV (\%) & 10,04 & 17,89 & $0,0 \pm 0,00 \mathrm{~d}$ & 19,86 \\
\hline
\end{tabular}

As médias \pm desvio padrão seguidas pelas mesmas letras nas linhas não diferem significativamente pelo teste Tukey a $5 \%$ de probabilidade.

Tabela 5. Efeito alelopático de extratos aquosos de folhas secas de guaçatonga (Casearia sylvestris) sobre alface (Lactuca sativa cv. grand rapids).

\begin{tabular}{ccccc}
\hline \multirow{2}{*}{ Concentração (\%) } & Germinação (\%) & \multicolumn{2}{c}{ Crescimento (cm) } & IVG \\
\cline { 2 - 4 } Controle & $98 \pm 0,45 \mathrm{a}$ & $2,1 \pm 0,55 \mathrm{a}$ & Sistema Radicular & $7,0 \pm 0,14 \mathrm{a}$ \\
10 & $94 \pm 0,89 \mathrm{a}$ & $2,0 \pm 0,51 \mathrm{a}$ & $4,5 \pm 0,55 \mathrm{a}$ & $6,1 \pm 0,38 \mathrm{a}$ \\
30 & $92 \pm 1,10 \mathrm{a}$ & $1,7 \pm 0,42 \mathrm{ab}$ & $2,8 \pm 0,55 \mathrm{ab}$ & $6,0 \pm 0,54 \mathrm{a}$ \\
50 & $92 \pm 0,45 \mathrm{a}$ & $1,3 \pm 0,29 \mathrm{ab}$ & $1,8 \pm 0,55 \mathrm{~b}$ & $2,0 \pm 0,51 \mathrm{~b}$ \\
70 & $80 \pm 1,58 \mathrm{ab}$ & $0,7 \pm 0,16 \mathrm{bc}$ & $1,8 \pm 0,55 \mathrm{~b}$ & $1,6 \pm 0,05 \mathrm{~b}$ \\
90 & $44 \pm 1,52 \mathrm{c}$ & $0,4 \pm 0,13 \mathrm{c}$ & $0,8 \pm 0,55 \mathrm{bc}$ & $0,7 \pm 0,04 \mathrm{c}$ \\
100 & $20 \pm 1,00 \mathrm{~cd}$ & $0,2 \pm 0,05 \mathrm{c}$ & $0,4 \pm 0,55 \mathrm{c}$ & $0,5 \pm 0,02 \mathrm{c}$ \\
\hline CV $(\%)$ & 852 & 20,56 & $19,540,55 \mathrm{c}$ & 14,32 \\
\hline
\end{tabular}

As médias \pm desvio padrão seguidas pelas mesmas letras nas linhas não diferem significativamente pelo teste Tukey a $5 \%$ de probabilidade. 
Tabela 6. Efeito alelopático de extratos aquosos de folhas secas de guaçatonga (Casearia sylvestris) sobre tomate (Lycopersicum esculentum).

\begin{tabular}{ccccc}
\hline \multirow{2}{*}{ Concentração (\%) } & Germinação (\%) & \multicolumn{2}{c}{ Crescimento (cm) } & IVG \\
\cline { 3 - 4 } Controle & $94 \pm 0,55 \mathrm{a}$ & $5,1 \pm 0,46 \mathrm{a}$ & Sistema Radicular & $3,5 \pm 0,97 \mathrm{a}$ \\
10 & $92 \pm 0,84 \mathrm{a}$ & $3,0 \pm 0,45 \mathrm{ab}$ & $9,7 \pm 1,00 \mathrm{a}$ & $3,0 \pm 0,35 \mathrm{a}$ \\
30 & $90 \pm 1,00 \mathrm{a}$ & $2,9 \pm 0,46 \mathrm{ab}$ & $4,7 \pm 0,29 \mathrm{~b}$ & $0,8 \pm 0,35 \mathrm{~b}$ \\
50 & $52 \pm 1,79 \mathrm{~b}$ & $1,6 \pm 0,43 \mathrm{~b}$ & $4,7 \pm 0,69 \mathrm{~b}$ & $0,6 \pm 0,02 \mathrm{~b}$ \\
70 & $38 \pm 1,30 \mathrm{bc}$ & $0,3 \pm 0,07 \mathrm{c}$ & $1,5 \pm 0,37 \mathrm{c}$ & $0,6 \pm 0,05 \mathrm{~b}$ \\
90 & $24 \pm 0,55 \mathrm{c}$ & $0,3 \pm 0,11 \mathrm{c}$ & $0,3 \pm 0,15 \mathrm{~d}$ & $0,5 \pm 0,13 \mathrm{~b}$ \\
100 & $14 \pm 1,67 \mathrm{c}$ & $0,3 \pm 0,05 \mathrm{c}$ & $0,3 \pm 0,12 \mathrm{~d}$ & $0,4 \pm 0,04 \mathrm{~b}$ \\
\hline CV (\%) & 17,87 & 15,73 & $0,3 \pm 0,5 \mathrm{~d}$ & 13,98 \\
\hline
\end{tabular}

As médias \pm desvio padrão seguidas pelas mesmas letras nas linhas não diferem significativamente pelo teste Tukey a $5 \%$ de probabilidade.

\section{CONCLUSÕES}

Conforme os resultados obtidos nos bioensaios pode-se concluir que $J$. princeps e $C$. sylvestris apresentam um potencial alelopático, sendo que os extratos aquosos das folhas e sementes dessas duas espécies causam efeitos inibitórios, confirmados pelo redução ou inibição da germinação e crescimento inicial e, também pelo atraso da germinação das espécies utilizadas (repolho, alface e tomate).

\section{REFERÊNCIAS}

Aquila MEA 2000. Efeito alelopático de Ilex paraguariensis A. St.-Hil. na germinação e crescimento inicial de Lactuca sativa L. Iheringia Ser Bot 53: 51-66.

Azevedo SKS, Silva IM 2006. Plantas medicinais e de uso religioso comercializadas em mercados e feiras livres no Rio de Janeiro, RJ, Brasil. Acta Bot Bras 20: 185-94.

Basile AC, Sertié JAA, Panizza S, Oshiro TT, Azzolini CA 1990. Pharmacological assay of Casearia sylvestris. I. preventive anti-ulcer activity and toxicity of the leaf crude extract. J Ethnopharmacol 30: 185-197.

Beiguelman B 2002. Curso prático de bioestatística. Ribeirão Preto: Funpec.

Bewley JD, Black M 1978. Physiology and biochemistry of seeds, in relation to germination. Berlim: Springer-Verlag.

Brasil 1992. Ministério da Agricultura e Reforma Agrária. Coordenação de Laboratório Vegetal. Regras para análise de sementes.

Chaves MMF, Davide AC 1996. Caracterização morfológica de frutos, sementes e plântulas de Joannesia princeps Vell. Euphorbiaceae. Rev Bras Sementes 18: 208-13.

Chiapuso G, Sánchez AM, Reigosa MJ, González L, Pellissier F 1997. Do germination indices adequately reflect allelochemical effects on the germination process? $J$ Chem Ecol 23: 2445-2453.

Chou CH, Yong CC 1974. Effects of osmotic concentration and $\mathrm{pH}$ on plant growth. Taiwania 19: 157-165.

Cruz-Ortega R, Anaya AL, Hernández-Bautista BE, LagunaHernández G 1998. Effects of allelochemical stress produced by Sicyios deppei on seedling root ultrastructure of Phaseolus vulgaris e Cucurbita ficifolia. J Chem Ecol 24: 2039-2057.

Elakovich SD 1999. Bioassays applied to allelopathic herbaceous vascular hydrophytes. In: Inderjit, Dakshini KMM, Foy CL (Ed.). Principles and practices in plant ecology. Boca Raton: CRC Press.

Ferreira AG, Áquila MEA 2000. Alelopatia: uma área emergente da ecofisiologia. Rev Bras Fisiol Veg 12: 175-204.

Ferreira AG, Borghetti F 2004. Germinação: do básico ao avançado. Porto Alegre: Artmed.

Iganci JRV, Bobrowski VL, Heiden G, Stein VC, Rocha BHG 2006. Efeito do extrato aquoso de diferentes espécies de boldo sobre a germinação e índice mitótico de Allium cepa L. Arq Inst Biol 73: 79-82.

Labouriau LFG 1983. A germinação das sementes. (Série Biologia, 24).Washington: Departamento de Assuntos Científicos e Tecnológicos da Secretaria Geral da Organização dos Estados Americanos.

Lopes WP, Silva AF, Souza AL, Meira-Neto JAA 2002. Estrutura fitossocióloga de um trecho de vegetação arbórea no parque estadual do Rio Doce - Minas Gerais, Brasil. Acta Bot Bras 16: 443-56.

Lorenzi H, Matos FJA 2002. Plantas medicinais no Brasil: nativas e exóticas. São Paulo: Nova Odesa.

Maguire JD 1962. Speed of germination-aid in selection evaluation for seedling emergence and vigour. Crop Sci 2: 176-177.

Maraschin-Silva F, Áquila MEA 2006. Contribuição ao estudo do potencial alelopático de espécies nativas. Rev Arvore 30: $547-555$.

Marchaim U, Werker E, Thomas WDE 1974. Changes in the anatomy of cotton seed coats caused by lucerne saponins. Bot Gaz 135: 139-146.

Medeiros ARM 1990. Alelopatia: importância e suas aplicações. Horti Sul 1: 27-32.

Miró CP, Ferreira AG, Áquila MEA 1998. Alelopaita de frutos de erva-mate (Ilex paraguariensis) no desenvolvimento do milho. Pesqui Agropecu Bras 33: 1261-1270.

Pellissier F 1993. Allelopathic inhibition of spruce germination. Acta Oecol 14: 211-218.

Piña-Rodrigues FCM, Lopes BM 2001. Potencial alelopático de Mimosa caesalpinaefolia Benth sobre sementes de Tabebuia alba (Cham.) Sandw. Floresta Ambient 8: 130-

\begin{tabular}{r|l}
\hline Rev. Bras. Farmacogn. & \multirow{2}{*}{929} \\
Braz. J. Pharmacogn. & \\
19(4): Out./Dez. 2009 &
\end{tabular}


136.

Pires NM, Souza IRP, Prates HT, Faria TCL, Filho IAP, Magalhães PC 2001. Efeito do extrato aquoso de leucena sobre o desenvolvimento, índice mitótico e atividade da peroxidase em plântulas de milho. Rev Bras Fisiol Veg 13: 55-65.

Rice EL 1984. Allelopathy. 2. ed. New York: Academic Press.

Rizvi SJH, Rizvi V 1992. Exploration of allelochemicals in improving crop productivity. In: Rizvi, SJH, Rizvi V. Allelopathy: basic and applied aspects. London, Chapman \& Hall.

Rizzini CT, Mors WB, Pereira NA 1988. Plantas brasileiras tidas como ativas contra peçonhas de animais, especialmente veneno de cobra. Rev Bras Farm 69: 82-86.

Rodrigues KCS 2002. Verificação da atividade alelopática de Myrciaria cuspidata Berg. (Camboim). Porto Alegre, 78p. Dissertação de Mestrado, Instituto de Biociências, Universidade Federal do Rio Grande do Sul.

Ruggiero PGC, Batalha MA, Pivello VR, Meirelles ST 2002. Soil-vegetation relationships in cerrado (Brazilian savanna) and semideciduous forest, Southeastern Brazil. Plant Ecol 160: 1-16.

Scavone O, Grecchi R, Panniza S, Silva RAP de S 1979. Guaçatonga (Casearia sylvestris Swartz): aspectos botânicos da planta, ensaios bioquímicos e propriedades cicatrizantes da folha. An Farm Quim 19: 73-81.

Soares GLG, Vieira TR 2000. Inibição da germinação e do crescimento radicular de alface (cv. grand rapids) por extratos aquosos de cinco espécies de Gleicheniaceae. Floresta Ambient 7: 180-197.

Válio IF, Scarpa FM 2001. Germination of seeds of tropical pioneer species under controlled and natural conditions. Rev Bras Bot 24: 697-701.

Waibel R, Benirschke G, Benirschke M, Achenbach H 2003. Sesquineolignans and other constituents from the seeds of Joannesia princeps. Phytochemistry 62: 805-811. 